\title{
O DIREITO A PARTES SEPARADAS DO CORPO HUMANO VIVO: QUESTÕES LEGAIS E ÉTICAS
}

\author{
Ana Paula Pavanini Navas ${ }^{1}$ \\ Luciano Ferreira Rodrigues Filho ${ }^{2}$
}

Resumo: O artigo trata questões legais e éticas sobre o direito a partes separadas do corpo humano vivo, sob a ótica dos direitos da personalidade e da bioética, passando pelo direito patrimonial e penal. Envolve a separação voluntária e involuntária de partes do corpo humano, e o direito de ação (realizar a separação) e pertencimento (posse) relativos à parte separada, desde sangue, órgãos humanos, incluindo os sexuais, a placenta, e a prática da placentofagia, trazendo questões, também, quanto a bens não considerados como parte do corpo pela legislação. $O$ método dedutivo e a revisão bibliográfica permeiam a desenvolvimento do assunto.

Palavras-chave: Direitos da personalidade; Bioética; Separação; Corpo humano; Placentofagia.

\section{THE RIGHT TO SEPARATE PARTS OF THE LIVING HUMAN BODY: LEGAL AND ETHIC ISSUES}

\begin{abstract}
The article deals with legal and ethical issues about the right to separate parts of the living human body, from the perspective of personality rights and bioethics, through patrimonial and criminal law. It involves the voluntary and involuntary separation of parts of the human body, and the right of action (to separate) and belonging to the separate part, from blood, human organs, including the sexual organs, to the placenta, and the practice of placentophagy, bringing questions, too, regarding goods not considered part of the body by legislation. The deductive method and the bibliographic review permeate the development of the subject.
\end{abstract}

Keywords: Personality rights; Bioethics; Separation; Human body; Pplacentophagy.

\footnotetext{
${ }^{1}$ Mestranda em Ciências Jurídicas pela Universidade Estadual do Norte do Paraná - UENP. Especialista em Direito Constitucional e Tributário pela Universidade do Sul de Santa Catarina - Unisul. Graduada em Direito pela Universidade Estadual do Norte do Paraná - UENP. Analista Judiciária do Tribunal Regional Eleitoral do Paraná.

${ }^{2}$ Mestre em Psicologia Social pela Pontifícia Universidade Católica de São Paulo-PUC/SP, membro do Núcleo de Estudos e Pesquisa Trabalho e Ação Social - NUTAS. Pesquisador do Grupo de Pesquisa em Constituição, Educação, Relações de Trabalho e Organizações Sociais - GPCERTOS, do curso de Direito da Universidade Estadual do Norte do Paraná - UENP. Docente do curso de Direito da Faculdade de Ibaiti - Universidade Brasil. Coordenador do Núcleo de Estudos Subjetividade e Direito - NESDI/FEATI.
} 


\section{INTRODUÇÃO}

Atualmente o direito vem enfrentando novas questões concernentes aos direitos humanos e fundamentais no campo do direito privado. São questões cada vez mais controversas, principalmente quanto a autonomia do indivíduo, considerado em si mesmo, e sua liberdade de identidade, expressão e até mesmo, de disposição do próprio corpo. São questões concernentes ao que se chamou de direitos da personalidade.

O artigo tratará, mais especificamente, do direito a partes separadas do corpo, de modo que, nesse sentido, há um entrelaçamento necessário do direito com a bioética e o biodireito, matérias igualmente novas no mundo jurídico.

Ocorre, no entanto, que a medicina desenvolve-se em maior velocidade que o direito, e recentemente, costumes tem surgido e se acomodado na sociedade com certa rapidez, de maneira que a legislação, muitas vezes, não é capaz de acompanhar, a fim de promover a regulamentação da vida em sociedade, havendo, pois, lacunas para certos procedimentos que, outrora, foram entendidos como a prática de crime, como será relatado no trabalho.

Nesse sentido, justifica-se a pesquisa, a fim de trazer à lume novos comportamentos que geram polêmica quanto ao direito a parte separadas do corpo, e o que fazer com essa parte, após separada. Tratar-se-ão questões como o direito do embrião, direito à redesignação sexual, direito à placenta e à placentofagia, e até a partes que não são consideradas como corpo, como cabelo e unhas por exemplo, à lume da atualidade.

Diante disso, reuniu-se pesquisa bibliográfica e jornalística, a fim de fundamentar, a partir do método dedutivo, o direito a partes do corpo pelo indivíduo. Para tanto, necessária uma explanação breve do que são os direitos da personalidade, para, na sequência, adentrar em questões como transfusão de sangue, doação de órgãos, cirurgia de redesignação sexual e outros assuntos que tem tomado novos viéses interpretativos nos últimos anos.

\section{DIREITOS DA PERSONALIDADE}

Os direitos de personalidade são uma novidade legislativa no Brasil, tendo sido positivados no Código Civil de 2002, após alguns deles já terem sido reconhecidos, anteriormente, em leis esparsas. Tratou-se, então de atender uma nova ordem jurídica 
emergente, diante dos princípios e garantias previstos na Constituição Federal de 1988, muito além dos direitos previstos no Código Civil de 1916.

Assim, enquanto os direitos fundamentais são diretrizes gerais e garantia social para evitar o poder estatal excessivo, "os direitos da personalidade são fruto da captação desses valores fundamentais regulados no interior da disciplina civilística" (TARTUCE, 2015, p. 145), "como poderes que o homem exerce sobre a própria pessoa" (BITTAR, 2015, p. 34). Desse modo, "sempre que apreciados sob o prisma das relações privadas, no campo e como enfoque de estudo do Direito Civil, esses direitos chamam-se de 'direitos da personalidade"” (IBID., p. 32).

O reconhecimento de tais direitos, não apenas na ordem jurídica nacional, mas também, de certa forma, no direito comparado, não foi de pronto, já que havia grande discussão doutrinária acerca de sua existência. Conforme ensina Bittar, numa primeira fase, representada por autores como Thon, Unger, Jellinek, Ennecerus, Crome, Oertman, Von thur, Ravà, Simoncelli, Cabral de Moncada e Orgaz, negava-se a existência de direitos subjetivos, pois uma vez que o homem tivesse direito sobre si próprio, poder-se-ia justificar, inclusive, o suicídio. Numa fase posterior e mais atual, passou-se ao reconhecimento concreto de tais direitos, embora restando dúvidas quanto à sua natureza, sendo expoentes nomes como De Cupis, Tobeñas, Rauymond Lindon, Ravanas, Perlingieri, Limongi França, Milton Fernandes, Orlando Gomes, entre outros (IBID., p. 34).

Ainda antes da codificação, Limongi França dedicou parte de seu estudo aos direitos da personalidade, denotando um estudo apenas superficial com a questão de institutos de proteção à personalidade por parte de autores de sua época, de modo geral, ao passo que considerava a matéria com caracteres próprios, merecedores de estudo sistemático e de conceituação, para o que o ensina que os institutos de proteção à personalidade em sentido lato e estrito "são as instituições de Direito que, particularmente no setor privado e social, visam a garantir as faculdades das pessoas em relação a si mesmas, do mesmo modo que os bens exteriores indispensáveis a essa garantia”. (FRANÇA, 1972, p. 6-9)

Desse modo, sendo os direitos privados da personalidade aqueles que o próprio sujeito exerce, os institutos de proteção de tal espécie de direito trata-se de proteção à personalidade acometida a terceiros. (IBID., p. 9)

Personalidade, por sua vez, é conjunto de caracteres do próprio indivíduo, ainda que não nascido - já que no ordenamento pátrio atribui-se personalidade ao embrião e ao nascituro 
-, sendo o primeiro bem pertencente ao indivíduo, que lhe dará a possibilidade de adquirir e defender mais bens, inerentes à pessoa humana, a saber: a vida, a liberdade, a honra, entre outros. (SZANIAWSKI, 2005, p. 70)

Uma vez explanada a parte inicial e fundamental para a sustentação do trabalho, segue conceituação hodierna dos direitos da personalidade, segundo Tartuce (2015, p. 147):

\begin{abstract}
Observa-se que os direitos da personalidade têm por objeto os modos de ser, físicos ou morais do indivíduo e o que se busca proteger com eles são, exatamente, os atributos específicos da personalidade, sendo personalidade a qualidade do ente considerado pessoa. Na sua especificação, a proteção envolve os aspectos psíquicos do indivíduo, além de sua integridade física, moral e intelectual, desde a sua concepção até a sua morte. [...] pode-se afirmar que os direitos da personalidade são aqueles inerentes à pessoa e à sua dignidade (art. $1^{\circ}$, III, da CF/1988).
\end{abstract}

Assim, a personalidade, com o valor jurídico adquirido no ordenamento pátrio por meio da Codificação, para as pessoas físicas, porquanto não exista, exceto na jurisprudência, direitos de personalidade atribuíveis às pessoas jurídicas, informa e orienta direitos desse gênero tanto nas relações com o Estado, como entre os particulares, sendo considerados essenciais à pessoa humana, visando à proteção de sua dignidade. (BORGES, 2005, p. 14)

Englobando tais direitos os bens mais elevados da pessoa humana, "o ordenamento jurídico não pode consentir que deles se despoje o titular, emprestando-lhes caráter essencial. Daí, são, de início, direitos intransmissíveis e indispensáveis, restringindo-se à pessoa do titular e manifestando-se desde o nascimento (Código Civil de 2002, art. 2º)".(BITTAR, 2015, p. 43).

Alguns direitos de personalidade, no entanto, podem ser parcialmente disponibilizados por seu titular, diante de certas condições, observáveis de acordo com a espécie de direito. Várias são as classificações dos direitos à personalidade, e a título exemplificativo, optou-se pelo elenco trazido por Adriano de Cupis, a saber: o direito à vida e à integridade física, o direito sobre as partes destacadas do corpo e o direito sobre o cadáver, o direito à liberdade, o direito ao resguardo (direito à honra, ao resguardo e ao segredo), o direito à identidade pessoal (o direito ao nome, ao título e ao sinal pessoal), o direito moral do autor. (CUPIS, 2008, PASSIM)

Para o presente trabalho e demonstração da hipótese, qual seja, mostrar que é possível ter direito a separar partes do corpo e ter direito a elas após separadas, interessa o direito sobre as partes destacadas do corpo vivo, atendendo ao recorte proposto, para o que, 
no próximo tópico, serão dedicadas algumas linhas, divididas numa capítulo inicial um pouco maior, acerca da separação voluntária de partes do corpo, no sentido de que tais partes não são destacáveis sem ação humana, e um segundo capítulo ligeiramente menor, sobre a separação involuntária de partes do corpo vivo, no sentido de que a separação ocorrerá por circunstâncias externas à ação voluntária humana.

\subsection{Separação voluntária de partes do corpo vivo}

A separação de partes do corpo vivo, no ordenamento internacional, via de regra obedece à normas de direito positivo do país. Normalmente atrelada à dignidade da pessoa humana, tais normas prevêem formas de tal separação e seu caráter altruístico ou patrimonial.

De fato, embora desde sempre por razões religiosas e éticas, o corpo humano é bem fora do comércio, diante da identificação do corpo com a pessoa, e o reconhecimento da dignidade intrínseca à condição humana, não podendo ser admitido, com sensatez, a essa altura de desenvolvimento, o comércio do corpo humano, havendo, no entanto, dúvida acerca da mesmo posicionamento quando se fala de partes separadas do corpo humano. (BERGEL, 2013, p. 200)

Assim, diante dessa concepção holística, o corpo humano, inteiro, em si, não pode ser comercializado ou negociado, quer a título gratuito, quer a título oneroso. No entanto, o direito positivo moderno, diante do desenvolvimento dos estudos na área de saúde e bioética, admitem, pacificamente, a separação de partes do corpo humano, com restrições, a título gratuito ou oneroso, a depender do país.

Nesse sentido, podem ser destacados do corpo vivo, voluntariamente, o sangue, óvulos, sêmen, órgãos duplos - apenas um deles - que não gerem deformidade permanente, partes de órgãos regeneráveis, tecidos, células em geral, sendo que, mais modernamente, admite-se a separação voluntária do cabelo, como parte do corpo humano.

Em alguns países, há regramento quanto ao caráter (não) patrimonial de tais bens do indivíduo, de modo que, a depender a que título determinada parte do corpo é destacada, pode-se, inclusive, infringir norma legal, ainda que o indivíduo tenha desejado a operação.

De qualquer modo, devem ser atendidos os princípios norteadores da Bioética, sempre que se tratar de separação voluntária do corpo vivo, como o da beneficência, 
autonomia e justiça. Em relação a tais princípios, merece transcrição os ensinamentos de Meirelles (2001, p. 89):

\begin{abstract}
Assim, o princípio da beneficência seria colocado no vértice, correspondendo ao fím primário da Medicina que, numa visão naturalista, é o de promover o bem, em relação ao paciente ou à sociedade, evitando o mal.

O princípio da autonomia refere-se ao respeito que se impõe à autodeterminação humana, fundamentando a aliança terapêutica entre método e paciente e o consentimento aos diversos tipos de tratamentos colocados a seu serviço.

O princípio da justiça relaciona-se à justa distribuição dos benefícios dos serviços de saúde, resumindo-se na obrigação de igualdade de tratamento, respeitadas as diferenças de situações clínicas, evidentemente, bem como a proporcionalidade das intervenções.
\end{abstract}

A seguir, algumas considerações pertinentes sobre a doação de sangue, medula óssea e órgãos inter vivos, com atenção aos princípios acima, e de material genético e separação de órgãos sexuais, além de outras partes destacáveis do corpo humano, como unha e cabelo.

\title{
2 DOAÇÃO DE SANGUE, TECIDO, MEDULA ÓSSEA E ÓRGÃOS INTER VIVOS
}

Desse modo, no Brasil, admite-se, sempre a título gratuito, ou seja, a título de doação, a separação do sangue, tecidos e de órgãos, por motivos altruísticos, havendo, portanto, vedação do comércio e, consequentemente, atribuição de caráter patrimonial a tais bens, no país. Tem-se presente o princípio da beneficência, no sentido claro de promoção do bem à sociedade.

O doador vivo deverá ser pessoa capaz diante da lei civil, havendo a denotação, aí, do princípio da autonomia, de maneira que o Código de Ética Médica, aprovado pela Resolução do Conselho Federal de Medicina n. 1.931/2009, em seu artigo 45, proíbe ao médico a retirada de órgão de doador vivo juridicamente incapaz, mesmo se houver autorização de seu representante legal, excetuados casos permitidos e regulamentados em lei, tal qual se fez quanto à questão da doação de medula óssea, a partir da Lei n. 9.434. Nota-se, também, uma faceta do princípio da justiça nesse contexto.

De fato, a Lei n. 9.434, de 04 de fevereiro de 1997, regulamentada pelo Decreto $\mathrm{n}$. 9.175, de 18 de outubro de 2017, trata a disposição de órgãos, tecidos, células e partes do corpo humano para fins de transplante e tratamento. Sobre a disposição do corpo vivo, o art. 27 do regulamento traz que órgãos, tecidos, células e partes do corpo podem ser retiradas em 
vida, para fins de transplante ou enxerto, devendo os órgãos, nesse caso, serem duplos e a remoção de um deles não representar risco para a integridade física ou grave comprometimento de aptidões vitais, tampouco mutilação ou deformação inaceitável.

Nesse sentido, é relativamente comum, não apenas no Brasil, mas em outros países cujas técnicas de transplantes já estejam avançadas e exista um consenso bioético da classe médica e jurídica, a realização de transplantes de rins, órgão duplo, cuja remoção não causará transtornos permanentes ao doador, tampouco lhe causará deformação inaceitável.

Nesse sentido, dispõe o Código de ética que o médico deve

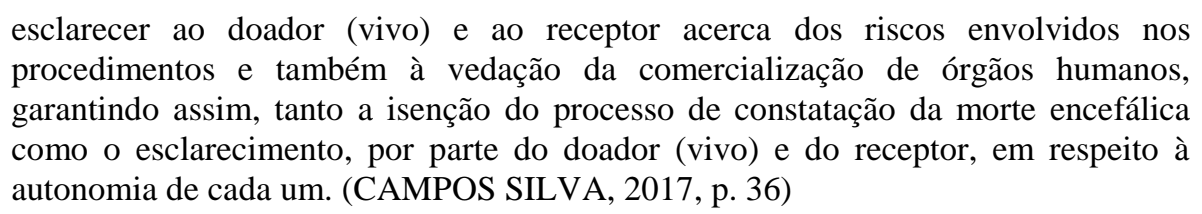

Mas seria realmente necessária essa previsão legal acerca dos riscos e vedações quanto à doação entre vivos, principalmente na questão da mutilação e deformidade?

Ocorre que, como bem pontuou Habermas, a modernidade trouxe à lume uma nova compreensão de liberdade e autonomia, que precisa ser normativamente regulamentada, já que não se pode admitir que determinadas transformações que dependam de preferências não admitam qualquer tipo de limitação (HABERMAS, 2010, p. 18). Nesse sentido, se um indivíduo optasse por doar uma córnea, por ter outra, sem a limitação legal quanto à deformação e transtornos, o procedimento seria autorizado, caso o doador concordasse. No entanto, a própria lei cuidou de criminalizar condutas do tipo, no art. 14 , parágrafo $3^{\circ}$ e incisos.

Logo, em havendo possibilidade legal e médica, admite-se, no Brasil, a doação, a título gratuito, de sangue, tecido e órgãos duplos, com as ressalvas normativas. A compra ou venda de tecidos, órgãos ou partes do corpo humano é tipificada como crime, conforme leitura do art. 15.

O caráter de tal doação é altruístico, considerando a nobreza do ato de poder salvar uma vida, sendo admitida pacificamente, no Brasil, a doação de órgãos entre parentes, e mais restritamente, a doação entre pessoas sem vínculo sanguíneo, desde que haja autorização judicial para tanto, nos termos do art. $9^{\circ}$ da Lei n. 9.434 . 


\subsection{Doação de sêmen e óvulos: o comércio "disfarçado" de material genético}

Diante das novas tecnologias na área da medicina reprodutiva, é possível, hoje, que filhos sejam gerados in vitro, e posteriormente implantados no útero de uma mulher. Diante de inúmeros problemas de infertilidade que casais tem enfrentado, e da admissão, pelos ordenamentos modernos do ocidente, da geração de filhos por casais homossexuais ou mesmo produção independente, recorre-se a bancos de material reprodutivo: sêmen e óvulo de doadores e doadoras anônimos, mas cujas características constam do catálogo.

Nesse sentido, atualmente há possibilidade de se recorrer a tais bancos para possibilitar a reprodução, falando-se, até mesmo, em "fábrica de filhos loiros", diante da preferência por esse biotipo ${ }^{34}$. O custo para mantenimento de tal material é alto, considerando o processo de criopreservação ou crioconservação, técnica "usada para o congelamento de espermatozoides, óvulos, embriões e tecidos gonadais" (ALMODIN; COSTA, 2011, p., 3). Nesse sentido, paga-se um custo pelo mantenimento de tal material genético ao mantenedor que causa confusão quanto à questão da comercialização ou não do material genético, que de certo modo acaba ocorrendo pela clínica mantenedora - , devendo restar, no entanto, a doação por parte do homem ou mulher que cedeu o material. Isso se deve ao fato de que, no Brasil, a medicina reprodutiva seja basicamente um campo de atuação do setor privado, subvertendo a lógica tradicional da pesquisa e ensino médico no país. (DINIZ, 2002, p. 203)

A Constituição Federal de 1988 já previu no art. 199, parágrafo 4º que "a lei disporá sobre as condições e os requisitos que facilitem a remoção de órgãos, tecidos e substâncias humanas para fins de transplante, pesquisa e tratamento, bem como a coleta, processamento e transfusão de sangue e seus derivados, sendo vedado todo tipo de comercialização.”

No entanto, não obstante disposição constitucional brasileira, a evolução técnica que impulsionou a multiplicação das possibilidades no campo da reprodução assistida e aceitação social, cada vez mais crescente, dessa opção por parte de casais heterossexuais ou homoafetivos que desejam ter filhos, fez

\footnotetext{
3 Cf. Sêmen de 'loiros altos' torna Dinamarca 'meca' da inseminação artificial. Disponível em: http://g1.globo.com/mundo/noticia/2011/05/semen-de-loiros-altos-torna-dinamarca-meca-de-inseminacaoartificial.html. Acesso em 14 jul 2018.

${ }^{4}$ Cf. Eugenia: brasileiros que importam sêmen dos EUA viram notícia internacional. Disponível em: http://www.socialistamorena.com.br/eugenia-brasileiros-que-importam-semen-dos-eua-viram-noticiainternacional/. Acesso em 14 jul 2018.
} 
"acender motivações que se apresentam intrinsecamente ligadas tanto ao aumento da "oferta" dos serviços ligados à reprodução assistida (como a busca do lucro, quer por parte das empresas envolvidas, médicos, pesquisadores, e mesmo intermediários) quanto da "demanda" por estes mesmos serviços (o desejo humano funcionando como um "motor" para a busca da felicidade). (LEWICKI, 2001, p. 103-104)

Nota-se, dessa maneira, que não obstante ao doador, peça principal e condição sine qua non para o evento exitoso da reprodução assistida ou desenvolvimento de pesquisas com embriões, permaneça a obrigatoriedade da gratuidade pelo ato, outros atores "comercializam" sob a forma de manutenção de custos ou algo do gênero o material genético diante da ausência de participação do setor de saúde pública, como já é feito quanto à doação de sangue e doação de órgãos. O setor público de saúde reprodutiva deve, a medida do possível, procurar promover melhorias no sentido de propiciar, aqueles que desejam receber o material genético, a gratuidade, como princípio que estimula a solidariedade e previne os interesses de ordem financeira que podem estar envolvidos. (BRAUMER, 2003, p. 90)

Outra questão quanto ao material genético doado é o que fazer com aquilo que não foi utilizado ou propositalmente produzido em excesso para utilização futura, o que pode vir de não acontecer. $\mathrm{O}$ maior debate em relação ao assunto se dá quanto às células-tronco embrionárias, sua utilização para fins terapêuticos e de pesquisa, e modos de intervenção, agressão e destruição do embrião humano, sendo que,

No Brasil, a utilização de células-tronco embrionárias encontra-se regulada pelo artigo $5^{\circ}$ da Lei n. 11.105, de 24 de março de 2005 (Lei de Biossegurança). O referido dispositivo legal foi objeto de Ação Direta de Inconstitucionalidade n. 3.510, que, em que pese a divergência dos votos acerca do marco inicial da vida, assim como referentes ao prazo de criopreservação e aos métodos alternativos existentes, foi julgada improcedente, por maioria de votos. Logo, é permitida a utilização, para fins de pesquisa e terapia, de células-tronco embrionárias obtidas de embriões humanos produzidos por fertilização in vitro, consideradas inviáveis e criopreservadas há mais de três anos. (BARRETO; LAUXEN, 2017, p. 3)

Nesse sentido, após amplo debate em sede constitucional quanto à utilização de material genético ainda não implantado, decidiu-se pela constitucionalidade de seu uso, nos termos da lei mencionada. 


\subsection{Remoção de órgãos sexuais: "transgenitalização", "adequação de sexo" ou "cirurgia de redesignação sexual"?}

Outro item de debate quando o assunto é separação de partes do corpo vivo é a questão referente ao gênero, que pode dar ensejo à cirurgia de redesignação sexual (nomenclatura mais adequada), mais conhecida, popularmente, como transgenitalização. O início da controvérsia já diz mesmo à própria terminologia, posto que a primeira delas já é afeta à nomenclatura, de maneira que transexual é o nome que se atribui a "um indivíduo que possui o sentimento irreversível de pertencer ao sexo contrário ao que foi genética e morfologicamente estabelecido, ou seja, que não se identifica com seus genitais biológicos e suas atribuições socioculturais" (GALLI et al, 2013, p. 448). A eles, cabe a cirurgia de redesignação sexual, que de modo recorrente, "tem sido considerada um componente importante do processo transexualizador, a ponto de ter sido incluída na pauta da agenda da saúde pública”. (IBID., p. 447)

Nem sempre foi assim, no entanto, já que não se trata de órgão duplo ou regenerável a ser extraído. Antonio Chaves, nos idos da década de 70, discorreu sobre o assunto em Conferência realizada na Europa, quanto à ausência, à época, de legislação específica sobre o assunto, devendo ser admitido que operações tais quais a de redesignação sexual não poderiam mais ser consideradas contrárias à ordem pública ou aos bons costumes, devendo ficar a critério do intérprete decidir se a evolução científica impõe ou não uma ampliação do conceito de integridade física para o não menos importante de integridade psíquicas. (CHAVES, 1980, p. 193).

Tal avaliação de fatos tornou-se evidentemente necessária, em especial no Brasil, após o caso do cirurgião plástico Roberto Farina. Chaves (1977, p. 273) explica que

\footnotetext{
No XV Congresso Brasileiro de Urologia, realizado em novembro 1975, o cirurgião plástico Roberto Farina, docente da Escola Paulista de Medicina, expondo uma tese, exibiu um filme de sua cirurgia de reversão sexual realizado em 1971, anunciando que a havia executado em nove pacientes masculinos. [...]

Dentre as muitas reações provocadas pela comunicação, uma foi inesperada e rumorosa: ao tomar dela conhecimento pela imprensa, o Ministério Público de S. Paulo, através do Promotor Messias Paiva, da $17^{\mathrm{a}}$ Vara Criminal da Capital, denunciou o cirurgião, em agosto de 1976, como incurso nas penas do art. 129, parágrafo $2^{\circ}$, inciso III do Código Penal, por ter cometido lesões corporais de natureza grave, causando perda ou inutilização de membro, sentido ou função, cominadas com pena de reclusão de dois até oito anos.
} 
Não obstante tais situações não mais se repitam, e ao final do caso, tenha sido o cirurgião inocentado, as cirurgias para redesignação sexual ainda carecem de legislação específica, de maneira que a matéria é regida pela Resolução 1955/2010 do Conselho Federal de Medicina.

Fator interessante é que a transexualidade era, até bem recentemente, considerada doença associada a transtorno mental pela agência de saúde da Organização das Nações Unidas (ONU), mas no dia 18 de junho de 2018, o Organização Mundial da Saúde (OMS), publicou, em seu site, nova revisão do manual de Classificação Internacional de Doenças (CID-11) que remove a transexualidade, ou incongruência de gênero, da lista de transtornos mentais, recebendo a condição de condição relativa à saúde sexual. ${ }^{5}$ A OMS entende ser agora evidente que não se trata de um transtorno mental, e que, em verdade, classificar o transexualismo desse modo pode causar enorme estigma para os transgêneros. ${ }^{6}$

Desse modo, torna-se evidente que a decisão da OMS pautou-se pela dignidade da pessoa humana e direito de autonomia do indivíduo, devendo, então, essa mesma dignidade servir de parâmetro para aplicação, interpretação e integração de todo o ordenamento jurídico (MARTINS, 2012, p. 63-64). Assim, entende-se que a ablação de órgão sexual cujo transgênero não se identifique trata-se de ato legal, tendo então, o indivíduo, direito de tê-lo removido de seu corpo, sem que isso se configure lesão corporal.

\subsection{Unhas e cabelos: ausência de regulamentação}

Unhas e cabelos não são considerados bens fora do comércio ou partes separadas do corpo, regidas pelos direitos da personalidade. Talvez pela possibilidade de destacá-los sem prejuízo de saúde ou sem causar dor física, sendo hábitos impostos e necessários desde os primeiros dias de vida, o legislador brasileiro não se preocupou em disciplinar a separação de tais partes do corpo.

No entanto, em tempos recentes tem surgido um comércio de cabelo, impulsionado pelo modismo do megahair com fios naturais, de maneira que muitas mulheres, e até mesmo alguns homens, adeptos dos fios longos, ao cortar suas madeixas, acabam vendendo-as para

\footnotetext{
${ }^{5}$ Cf. OMS retira transexualidade da sua lista de doenças. Disponível em: https://www.revistaforum.com.br/omsretira-transexualidade-da-sua-lista-de-doencas/. Acesso em 14 jul 2018.

${ }^{6} \mathrm{Cf}$. ICD-11: Classifying disease to map the way we live and die. Disponível em: http://www.who.int/healthtopics/international-classification-of-diseases. Acesso em 14 jul 2018.
} 
clientes interessados em implantá-las na cabeça de outras pessoas. Ainda, hospitais especializados e tratamento contra o câncer promovem ações no sentido de que aqueles que desejam diminuir a altura do corte façam a doação do cabelo retirado para instituições que confeccionam perucas e apliques para os paciente que sofrem com a queda de cabelo gerada pelo tratamento contra a doença. Esses fatos, conjugados, geraram uma demanda maior que a oferta, de maneira que existe, hoje, a possibilidade de atribuição financeira ao cabelo, que pode até mesmo ser objeto de furto ou roubo, e objeto de tutela penal, não obstante não tutelados pelos direitos da personalidade.

Logo, embora do ponto de vista do direito da personalidade cabelos não sejam considerados partes separadas do corpo a merecerem atenção legislativa, do ponto de vista patrimonial é possível entender como crime de furto ou roubo a separação do cabelo do corpo da vítima, ainda que indolor fisicamente. ${ }^{7}$ Apesar da máxima "cabelo cresce", é importante notar que, não obstante a omissão da legislação civil em proteger o direito ao cabelo, a lei penal tem procurado punir aquele que, de alguma forma, retira cabelo de outrem sem autorização, podendo, em casos mais graves, aventar-se até mesmo a possibilidade de danos morais, diante do caso concreto. ${ }^{8}$

O mesmo raciocínio aplica-se às unhas de um determinado indivíduo. Não obstante para a imensa maioria das pessoas tratar-se de parte do corpo a ser jogada ao lixo quando separada, seja por corte ou por lixamento, alguns indivíduos realmente cultivam unhas longas por motivos pessoais ou profissionais, que devem ensejar uma proteção legal, caso sejam separadas do corpo.

O caso mais emblemático a ilustrar essa afirmação é o do indiano Shridhar Chillal, que ficou 66 anos sem cortar sua unhas da mão esquerda, e após ter-se tornado deficiente permanente de tal membro, acabou por cortá-las e vendê-las, garantindo uma aposentadoria, após ostentar diversos recordes mundiais. ${ }^{9}$

De fato, quando se para a pensar, embora em linhas gerais cabelos e unhas pareçam não merecer a tutela dos direitos da personalidade, pelo hábito cultural de serem destacados e

\footnotetext{
${ }^{7}$ Cf. Roubos de cabelo só aumentam no País; madeixas podem custar mais que ouro. Disponível em: https://noticias.r7.com/domingo-espetacular/fotos/roubos-de-cabelo-so-aumentam-no-pais-madeixas-podemcustar-mais-que-ouro-22022016\#!/foto/1. Acesso em 14 jul 2018.

8 Cf. 'Nunca tinha cortado', diz menor que teve cabelos roubados em Rio Preto. Disponível em: http://g1.globo.com/sao-paulo/sao-jose-do-rio-preto-aracatuba/noticia/2013/04/nunca-tinha-cortado-diz-menorque-teve-cabelos-roubados-em-rio-preto.html. Acesso em 14 jul 2018.

${ }^{9} \mathrm{Cf}$. Dono das maiores unhas do mundo as corta e ganha grana o suficiente para se aposentar. Disponível em: https://gizmodo.uol.com.br/dono-maior-unha-mundo-corta-aposentadoria/. Acesso em 14 de jul 2018.
} 
desprezados, em alguns casos é necessário dar ao portador de tais bens uma tutela efetiva quando tiverem seus direitos de manter cabelos e unhas junto ao corpo violados, sem que tenha concorrido com sua própria autonomia da vontade para tanto.

\section{SEPARAÇÃO INVOLUNTÁRIA DE PARTES DO CORPO: DENTES E PLACENTA}

Passada a fase inicial da separação de partes do corpo de forma voluntária, ou seja, daquela regida pela autonomia da vontade, ou, mesmo que contra essa, exija, para o sucesso da separação, uma intervenção humana, seja pelo corte, punção, incisão ou qualquer outro procedimento voluntário e criado pelo ser humano, interessante ressaltar a ocorrência da separação de partes do corpo humano de forma involuntária, isto é, pela expulsão natural de tal parte, como ocorre com os dentes em todos os humanos, durante a infância, e como ocorre com a placenta, no caso da mulher, em virtude de gestação.

Novamente não há legislação voltada ao estudo dos direitos da personalidade quanto à tutela de tais bens. Assim, quanto aos dentes, porquanto não tutelados civilmente, penalmente pode ser aplicada a proteção no que tange ao furto dos mesmo, e até mesmo lesão corporal, em caso de agressão que lhes quebrem ou arranquem pela raiz.

Mesmo a primeira dentição, que é naturalmente expelida pelo crescimento humano, é passível de apropriação e valoração, de maneira que, salvo juízo melhor, pertence o dente a criança ou ao seu responsável, quando de sua queda.

O mesmo raciocínio aplica-se à dentição permanente, que eventualmente poderá ser removida por questões médicas. Caso o indivíduo peça ao profissional dentes que foram arrancados, devem ser-lhe os mesmos providenciados. Esse fato é de fácil constatação, posto que até mesmo a documentação odontológica é do paciente, cabendo ao ortodontista ou cirurgião-dentista a guarda legal, de fiel depositário, dessa documentação, nos termos do art. 17 do Código de Ética Odontológica, constituindo infração negar ao paciente acesso a seu prontuário, nos termos do art. 18, inc. I. (CONSELHO FEDERAL DE ODONTOLOGIA, 2012).

Quanto à placenta humana, diante de "novas" práticas "velhas" quanto à sua destinação, nota-se uma necessidade, cada vez mais crescente, de tratamento legislativo quanto à sua proteção e destinação final. A placenta é o órgão responsável pela interface 
materno-fetal (APOLINÁRIO et al, 2003, p. 185), grosso modo, aquele responsável entre a troca de nutrientes entre mãe e feto. Surgido em virtude da gestação, após o parto, não guarda mais qualquer utilidade. Em um passado não tão distante, que algumas gerações de avós vivas ainda podem contar, os partos eram, majoritariamente, feito por parteiras e doulas, no próprio lar, sendo necessário que, após o procedimento, fosse dada destinação ao órgão, de maneira que, por questões sanitárias, era o mesmo, via de regra, enterrado. No entanto, há registros de que se comia, em algumas culturas, um pedaço da placenta, por questões mitológicas ou farmacêuticas, prática essa conhecida como placentofagia. Estudo feito na África do Sul revela que rituais placentários e outros conectados ao nascimento são comuns em várias sociedades, determinados por questões comportamentais e religiosas, e, contanto que não causem nenhum prejuízo, devem ser respeitados e não proibidos ${ }^{10}$ (BOGAERT; OGUNBANJO, 2008). Dentre esses rituais, um dos que causa estranheza é a prática de placentofagia, que tem se tornado cada vez mais frequente entre as mulheres, em especial dos Estados Unidos, Europa e até do Brasil, conforme pesquisado. ${ }^{11}$

Com a grande maioria dos partos no país feitos em hospital, a placenta, via de regra, trata-se de resíduo hospitalar, sendo naturalmente expulsa do corpo pelas contrações no parto normal, ou removida na cesárea. No entanto, algumas mães têm optado pelo parto de lótus, consistente em não cortar o cordão umbilical do recém-nascido, deixando-o ligado à placenta até seu desprendimento natural, que pode levar até 10 dias. ${ }^{12}$ Outras têm optado pela placentofagia. Assim, o que deve ser feito caso a mãe peça a placenta, órgão separado involuntariamente de seu corpo?

$\mathrm{Na}$ ausência de qualquer regulamentação a respeito, e considerando as práticas passadas de partos domésticos, quando a destinação do órgão ficava ao livre arbítrio da família, hospitais brasileiros tem entendido que, mantidos os cuidados necessários, o direito brasileiro assegura o pertencimento do órgão à mãe, baseando-se na liberdade religiosa e em questões ético-culturais. Desse modo, "não havendo disposição expressa da lei para que haja

${ }^{10}$ Placental rituals and other birth-by rituals are common in various societies. These rituals often include culturally determined behavioural sequences which operate as anxiety-releasing mechanisms and they serve to offer a spiritual means of 'control' over the future health and welfare of mother, child, and even the community. As long as such rituals do not cause them harm, they should be respected for the role that they play and be left alone.

${ }^{11} \mathrm{Cf}$. Placentofagia: saiba tudo sobre o ato e comer placenta. Disponível em https://vilamulher.uol.com.br/bemestar/saude/placentofagia-saiba-tudo-sobre-o-ato-de-comer-placenta-m1015-709877.html. Acesso em 14 jul 2018.

12 Cf. $\mathrm{O}$ que fazer com a placenta depois do parto? Disponível em: https://revistacrescer.globo.com/Gravidez/Pos-parto/noticia/2016/08/o-que-fazer-com-placenta-depois-oparto.html. Acesso em 14 jul 2018. 
o descarte da placenta para o lixo hospitalar, não há que se obrigar a dona (grife-se bem a palavra 'dona') do órgão a dispor sobre esta parte do seu corpo de tal maneira." (FELICIO JR., 2018)

De fato, não obstante seja livre a prática da placentofagia e destinação do órgão, não deixa de causar estranheza. Em Portugal, no ano de 2016, o Conselho Nacional de Ética para Ciências da Vida emitiu relatório classificando a placenta como resíduo hospitalar, sem dar explicação plausível, no entanto, sobre a sua natureza quando o parto é realizado em casa, e a mãe pode, em tese, fazer o que com o órgão bem entender. ${ }^{13}$ No Brasil, diante da ausência de regulamentação, aplica-se o entendimento da Agência Nacional de Vigilância Sanitária (ANVISA), no sentido de que, a partir do momento em que a família requisita a placenta, ela deixa de ser um Resíduo de Servico de Saúde (RSS). ${ }^{14}$

Outro exemplo do direito brasileiro que mostra que, mesmo sem legislação específica, a placenta pertence à genitora, pode ser vislumbrado no caso da Apelação Cível n. 0023056-79.2009.8.08.0024, que determinou indenização de $\mathrm{R} \$ 9$ mil para cada um dos pais do bebê, com as devidas correções, já que o sumiço do material (ou seja, da placenta), impossibilitou ao casal descobrir os motivos da morte do bebê e os possíveis riscos de uma segunda gravidez. ${ }^{15}$

Nesse sentido, enquanto não houver norma dando destinação legal à placenta, entende-se que o órgão pertence à mãe, ou aos pais, que podem, com ele, fazer o que bem entender, a partir do momento da separação do corpo.

Logo, urge que a legislação atente-se e adeque-se à rápida mudança de costumes observadas no Brasil, para que possam ser regulamentadas não apenas a questão referente à destinação da placenta, mas também de outras partes que, habitual e mais recentemente, são passíveis de separação do corpo.

\footnotetext{
${ }^{13}$ Cf. 86/CNECV/2016. Conselho Nacional de Ética para as Ciências da Vida. Destino da Placenta após o Parto. Disponível http://www.cnecv.pt/admin/files/data/docs/1453313820_P\%20CNECV\%2086_2016_Destino\%20Placenta.pdf. Acesso em 14 jul 2018.

14 Cf. Uso e consumo de Placenta. Disponível em: http://portal.anvisa.gov.br/resultado-debusca?p_p_id=101\&p_p_lifecycle=0\&p_p_state $=$ maximized\&p_p_mode $=$ view\&p_p_col_id $=$ column-

1\&p_p_col_count=1\&_101_struts_action=\%2Fasset_publisher\%2Fview_content \&_101_assetEntryId=287107 6\&_101_type $=$ content $\& \_101 \_$groupId $=219201 \& \_101 \_u r l T i t l e=$ uso-e-consumo-deplacenta\&inheritRedirect=true. Acesso em 14 jul 2018.

15 Cf. Indenização de R\$ 18 mil por sumiço de placenta. Disponível em: https://tjes.jusbrasil.com.br/noticias/363224259/indenizacao-de-r-18-mil-por-sumico-de-placenta?ref=amp. Acesso em 14 jul 2018.
} 


\section{CONCLUSÕES}

O direito a partes separadas do corpo transcende aquilo que é disciplinado pela lei Civil no tocante aos direitos de personalidade, atingindo nuances patrimoniais e, até mesmo, viés penal, diante da ausência de regulamentação legislativa concomitante à evolução dos costumes.

Reconhece-se o direito a partes separadas do corpo vivo não apenas por ação voluntária, quando da doação de sangue, órgãos e material genético, que nesse caso, deve ser gratuita, como também de partes que outrora não eram objeto de tutela, como cabelo e unhas, a depender, claro, do caso concreto, podendo esses dois últimos bens tomar, inclusive, contornos patrimoniais e ser objeto de tutela penal.

Com o advento das cirurgias de redesignação sexual não apenas órgãos duplos ou regeneráveis podem ser removidos de indivíduo, uma vez que, atendido o princípio da autonomia da vontade e da dignidade da pessoa humana, admite-se a ablação dos órgãos sexuais e reprodutivos de indivíduo transexual.

Por fim, tem-se que até mesmo aquelas partes separadas do corpo por ação diversa da autonomia da vontade, como dentes e placenta, devem ser objeto de proteção, cabendo, ao proprietário, ou seja, ao indivíduo cujo corpo os portava antes da separação, o direito a tais partes, devendo, tal situação, ser regulamentada, a fim de evitar que se firam os direitos da personalidade e direitos fundamentais de indivíduos.

\section{REFERÊNCIAS BIBLIOGRÁFICAS}

86/CNECV/2016. Conselho Nacional de Ética para as Ciências da Vida. Destino da Placenta após $\quad$ o $\quad$ Parto. Disponível em: http://www.cnecv.pt/admin/files/data/docs/1453313820_P\%20CNECV\%2086_2016_Destino \%20Placenta.pdf. Acesso em 14 jul 2018.

ALMODIN, Carlos Gilberto; COSTA, Rosaly Rulli. Criopreservação de gametas, embriões e tecido germinativo e laboratório de fertilização in vitro. Rio de Janeiro: Cultura Médica, 2011.

AGÊNCIA Nacional de Vigilância Sanitária. Uso e consumo de Placenta. Disponível em: http://portal.anvisa.gov.br/resultado-de-

busca?p_p_id=101\&p_p_lifecycle=0\&p_p_state=maximized $\&$ p_p_mode=view\&p_p_col_id $=$ column-

1\&p_p_col_count=1\&_101_struts_action=\%2Fasset_publisher\%2Fview_content\&_101_asse 
tEntryId=2871076\&_101_type=content\&_101_groupId=219201\&_101_urlTitle=uso-econsumo-de-placenta\&inheritRedirect=true. Acesso em 14 jul 2018.

APOLINÁRIO, Agnes Vânia; MIGLINO, Maria Angélica; PACHECO, Yolanda Galindo [et al]. Quantificação dos níveis de endotelina-1 em placentas e membranas fetais humanas. Brazilian Journal of Veterinary Research and Animal Science (2003) 40 (supl): 185-190, p. 185. Disponível em: http://www.scielo.br/pdf/bjvras/v40s3/25959.pdf. Acesso em 14 jul 2018.

BARRETO, Vicente de Paulo; LAUXEN, Elis Cristina Uhry. O marco inicial da vida humana: perspectivas ético-jurídicas no contexto dos avanços biotecnológicos. Cadernos de Saúde Pública. 2017; 33(6):300071816. Disponível em: http://www.scielo.br/pdf/csp/v33n6/1678-4464-csp-33-06-e00071816.pdf. Acesso em 14 jul 2018.

BERGEL, Salvador D. Aspectos éticos y jurídicos de la comercialización de partes separadas del cuerpo humano. Revista Bioética. 2013, p. 199-206.

BITTAR, Carlos Alberto. Os direitos da personalidade. 8 ed. rev., aum., e mod. São Paulo: Saraiva, 2015.

BOGAERT, D. Knapp van; OGUNBANJO G.A.. Post-birth rituals: ethics and the law. South African Family Practice. 50:2, 45-46. Disponível em: https://www.tandfonline.com/doi/pdf/10.1080/20786204.2008.10873693?needAccess=true. Acesso em 02 set 2018.

BORGES, Roxana Cardoso Brasileiro. Disponibilidade dos direitos de personalidade e autonomia privada. São Paulo: Saraiva, 2005.

BRAUMER, Maria Claudia Crespo. Direito, sexualidade e reprodução humana: conquistas médicas e o debate bioético. Rio de Janeiro: Renovar, 2003.

CAMPOS SILVA, Nilson Tadeu Reis; SEERA, Márcia de Fátima. A tutela dos transplantes sob a ótica dos direitos da personalidade. Rio de Janeiro: Lumen Juris, 2017.

CHAVES, Antônio. Direitos à vida, ao próprio corpo e às partes do mesmo (transplantes). Esterilização e Operações Cirúrgicas para "Mudança de Sexo". Direito ao cadáver e às partes dos mesmos. Revista da Faculdade de Direito da Universidade de São Paulo. V. 72, n. 1, 1977, pp. 243- 298. Disponível em: http://www.revistas.usp.br/rfdusp/article/view/66797/69407. Acesso em 14 jul 2018.

Castração, esterilização, "mudança" artificial de sexo. In: Revista da Faculdade de Direito da Universidade de São Paulo. V. 75, 1980, pp. 187-201. Disponível em: http://www.revistas.usp.br/rfdusp/article/view/66900. Acesso em 14 jul 2018.

CONSELHO FEDERAL DE ODONTOLOGIA. Código de ética odontológica. Aprovado pela Resolução CFO - 118/2012. Disponível em http://cfo.org.br. Acesso em 02 set 2018. 
CUPIS, Adriano de. Os direitos da personalidade. Tradução de Afonso Celso Furtado Rezende. São Paulo: Quorum, 2008.

DINIZ, Debora. Tecnologias reprodutivas, ética e gênero: o debate legislativo brasileiro. In: BARCHIFONTAINE, Christian de Paul de; PESSINI, Leo (orgs.). Bioética. Alguns desafios. 2 ed. São Paulo: Edições Loyola, 2002.

DONO das maiores unhas do mundo as corta e ganha grana o suficiente para se aposentar. Disponível em https://gizmodo.uol.com.br/dono-maior-unha-mundo-corta-aposentadoria/ Acesso em 14 de jul 2018.

EUGENIA: brasileiros que importam sêmen dos EUA viram notícia internacional. Disponível em: http://www.socialistamorena.com.br/eugenia-brasileiros-que-importam-semen-dos-euaviram-noticia-internacional/. Acesso em 14 jul 2018.

FELÍCIO JR., Rafael. $O$ direito sobre a placenta. Disponível em: http://www.egov.ufsc.br/portal/sites/default/files/anexos/31082-34125-1-PB.pdf. Acesso em 14 jul 2018.

FRANÇA, R. Limongi. Manual de Direito Civil. 2 vol. Tomo I, Livro I. Doutrina especial dos institutos de proteção à personalidade. Livro II. Doutrina especial do direito de família. São Paulo: Revista dos Tribunais, 1972.

GALLI, Rafael Alves; VIEIRA, Elisabeth Meloni; GIAMI, Alain [et al]. Corpos mutantes, mulheres intrigantes: transexualidade e cirurgia de redesignação sexual. Psicologia: Teoria e Pequisa. Out-Dez 2013. Vol. 29, n. 4, p. 447-457. Disponível em: http://www.scielo.br/pdf/ptp/v29n4/v29n4a11. Acesso em 14 jul 2018.

HABERMAS, Jürgen. O futuro da natureza humana. A caminho de uma eugenia liberal? Tradução de Karina Jannini. Revisão de tradução de Eurides Avance de Souza. 2 ed. São Paulo: WMF Martins Fontes, 2010.

INDENIZAÇÃO de R\$ 18 mil por sumiço de placenta. Disponível em: https://tjes.jusbrasil.com.br/noticias/363224259/indenizacao-de-r-18-mil-por-sumico-deplacenta?ref=amp. Acesso em 14 jul 2018.

LEWICKI, Bruno. O homem construível: responsabilidade e reprodução assistida. In: BARBOSA, Heloisa Helena; BARRETO, Vicente de Paulo (orgs.). Temas de biodireito e bioética. Rio de Janeiro: Renovar, 2001.

MARTINS, Flademir Jerônimo Belinati. Dignidade da pessoa humana. Princípio constitucional fundamental. 1 ed. 7 reimp. Curitiba: Juruá, 2012.

MEIRELLES, Jussara Maria Leal de. Bioética e biodireito. In: BARBOSA, Heloisa Helena; BARRETO, Vicente de Paulo (orgs.). Temas de biodireito e bioética. Rio de Janeiro: Renovar, 2001. 
O QUE fazer com a placenta depois do parto? Disponível em: https://revistacrescer.globo.com/Gravidez/Pos-parto/noticia/2016/08/o-que-fazer-complacenta-depois-o-parto.html. Acesso em 14 jul 2018.

PLACENTOFAGIA: saiba tudo sobre $o$ ato e comer placenta. Disponível em: https://vilamulher.uol.com.br/bem-estar/saude/placentofagia-saiba-tudo-sobre-o-ato-decomer-placenta-m1015-709877.html. Acesso em 14 jul 2018.

ROUBOS de cabelo só aumentam no País; madeixas podem custar mais que ouro. Disponível em: https://noticias.r7.com/domingo-espetacular/fotos/roubos-de-cabelo-so-aumentam-nopais-madeixas-podem-custar-mais-que-ouro-22022016\#!/foto/1. Acesso em 14 jul 2018.

SÊMEN de 'loiros altos' torna Dinamarca 'meca' da inseminação artificial. Disponível em: http://g1.globo.com/mundo/noticia/2011/05/semen-de-loiros-altos-torna-dinamarca-meca-deinseminacao-artificial.html. Acesso em 14 jul 2018.

SZANIAWSKI, Elimar. Direitos da personalidade e sua tutela. 2 ed. rev., atual. e ampl. São Paulo: Revista dos Tribunais, 2005.

TARTUCE, Flávio. Direito Civil 1. Lei de Introdução e Parte Geral. 11 ed. rev., atual. e ampl. Rio de Janeiro: Forense; São Paulo: Método, 2015. 